\title{
New Relationship in Carbon Cycle
}

\author{
Aleksei Naumov \\ Institute of Soil Science and Agrochemistry, Siberian Branch of Russian Academy of Sciences, Novosibirsk, Russia. \\ Email: a.naum@ngs.ru
}

Received October $31^{\text {st }}, 2012$; revised December $1^{\text {st }}, 2012$; accepted December $8^{\text {th }}, 2012$

\begin{abstract}
The problem of carbon dioxide accumulation in the atmosphere is closely related to the biological carbon cycle processes insufficiently studied from the global viewpoint. Based on data obtained from the literature on net primary production (NPP) and soil respiration (SR) of world ecosystems, a quantitative analysis of the relationship between these basic parameters of the production/destruction phase of the carbon cycle is offered in this paper. A direct correspondence (equality in carbon equivalent) is shown between the organic matter being generated (NPP) and the carbon dioxide release from soil into the air (SR). The established relationship is of fundamental nature because it shows a new aspect of the planet-scale mechanism.
\end{abstract}

Keywords: Biosphere; Biological Turnover; Carbon Balance; Dynamic Equilibration; Plant Productivity; Soil Respiration

\section{Introduction}

Global ecological problems related to changes in climate and environment, become a present-day reality. The global carbon cycle that joints the atmosphere, ocean and terrestrial ecosystems into an integrated whole has a paramount importance for biota and man. The cyclicality of exchange processes in biosphere results from activity of living organisms that populate our planet. The continuity of life implemented through reproduction and self-renewal, and the "pressure of living matter" in the environment both support a stable dynamic equilibrium of the global system.

The biological (biotical) cycle as a manifestation of the general regularity of interaction between living and inert matter in the limited space of biosphere is implemented through a multitude of chemical and biochemical reactions as well as physical and physicochemical processes. A special part in this aggregate is played by such processes as new organic matter generation by primary producers, synthesis of structural biomass and decomposition (destruction, mineralization) of organic matter down to primary components. However acute the problem seems to be, the mechanism of carbon cycle functioning is far from being sufficiently studied on the planet scale. A number of issues regarding sources and sinks, controlling factors, or dynamic characteristics of basic carbon flows still remains unclear. Additionally, debates about reason of the global warming and accumulation of greenhouse gases in the atmosphere last.
The anthropogenic factor-the growth of population and industrial production that results in the increasing burden on natural resources of biosphere-may well be a triggering mechanism for structural and functional changes on the global scale. In view of the urgency and actuality of the problem, the tasks of collecting and promptly processing data about conditions in which the atmosphere, ocean, land, and aquatic/terrestrial ecosystems exist in different parts of the world become those of primary importance [1]. The formation of open databases would allow the efficient use of the intellectual potential of different scientific associations and research groups.

\section{Basic Analysis of Data}

The net primary production and the annual (total) emission of $\mathrm{CO}_{2}$ are basic indicators describing the rate of generation and decomposition of organic matter in the biosphere. So far, it is not enough fundamental knowledge in understanding the processes of the global carbon cycle, but simulation models associate with climatic parameter, reflect only importance of the feedbacks, but not terminated picture [2]. Therefore collection and processing primary experimental data, including statistical methods and modeling, is an important stage in decision of the global problem. Table 1 shows some available in scientific literature global annual estimations to net primary production and soil respiration.

The data spread is considerable to use them in censorious balancing calculation. Global net simulation models 
taking into account different feedbacks between vegetation, climatic and ecological factors, also give very broad range of the NPP values: 43 - $79 \mathrm{Pg} \mathrm{C} \cdot \mathrm{yr}^{-1}$ [3-5]. The study of global carbon cycle is allied to difficulty of the reception of representative data sets. High-quality data sets based upon field observations of net primary productivity (NPP) are important to calibrate, parameterize, and evaluate terrestrial biosphere models [6]. Therefore, the collection and processing of primary experimental data including statistical methods and simulation would be an important step in solving a global problem.

The objective of our report is to show a quantitative relationship between the above indicators using accessible data sets in literature sources [12,20]. Special features and regularities of soil respiration function distribution in geographical space have been studied by the author earlier [21].

Figure 1 shows the distribution of net primary production and soil respiration relative to geographic latitude (based on data from the literature). The regularity found

Table 1. Global NPP and SR estimates from literature sour-

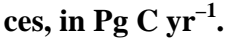

\begin{tabular}{cc}
\hline Net Primary Production [Ref.] & Soil Respiration [Ref.] \\
\hline $50-60[7-10]$ & $50[11]$ \\
$77[13,14]$ & $63-68[7,10,12]$ \\
$85-95[16,17]$ & $70-75[14,15]$ \\
& $77-80[18,19]$ \\
\hline
\end{tabular}

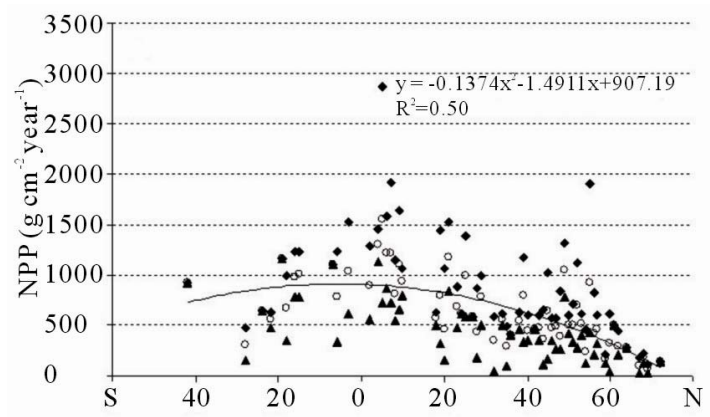

(a)

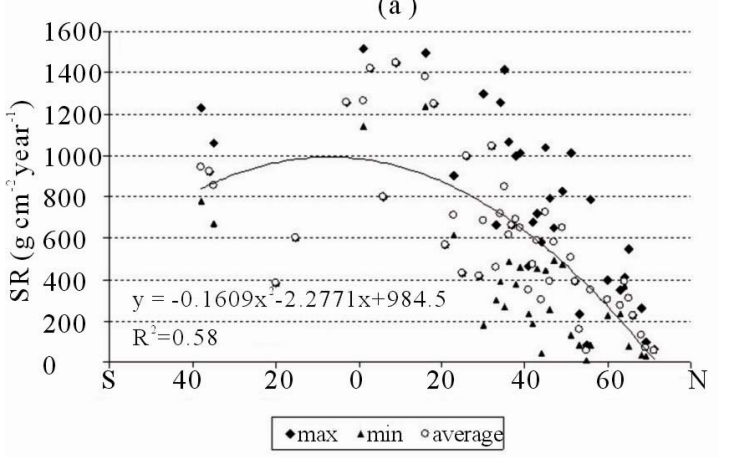

(b)

Figure 1. Geographical distribution and interpolation functions of NPP and SR indexes. by many researchers in distribution of the flow of solar energy coming to the earth surface from an external source and the respective latitudinal zoning of basic vegetation types are an important reason to search global ecological interrelations in biosphere. The second coordinate (longitude) is less important. Generally, its influence accounts for water supply of habitats and is indirectly manifested in the variety of ecosystems within each large biome and in the variation range of production/destruction phase parameters.

To make the presentation and processing of the material more convenient, initial sets of data were subdivided into intervals with a step of one degree in latitude. Maximum, minimum and mean values of indicators (NPP, SR) were found within each interval. The relationship between the characteristics being studied and the geographical latitude was then approximated as a quadratic parabola. The relationship between the primary production NPP and the soil respiration SR was assessed using a parameter $\boldsymbol{\xi}$ calculated with a one degree step as well for the whole range of available data:

$$
\xi=\mathrm{Y}_{\mathrm{SR}} / \mathrm{Y}_{\mathrm{NPP}}=\frac{\left(-0.1609 \mathrm{x}^{2}-2.2771 \mathrm{x}+984.5\right)}{\left(-0.1374 \mathrm{x}^{2}-1.4911 \mathrm{x}+907.19\right)}
$$

where $Y_{S R}$ and $Y_{N P P}$ are functions of soil respiration and primary production, respectively. The carbon content in dry organic matter of NPP was supposed to be $45 \%$.

Values obtained for the relationship being studied proved to be close to unity: $\xi=1.00 \pm 0.08(\overline{\mathrm{A}} \pm \sigma)$. In consideration of the presentability of the primary data sampling that covered different parts of earth and a great variety of studied ecosystems, the equality of NPP and $\mathrm{SR}$, i.e. basic parameters of biological carbon cycle on the global scale, could be assumed as an established fact. J. W. Earlier Raich and W. H. Schlesinger [12] have found the linear dependence between soil respiration and net primary production of nine bioms of the world as SR $=1.24(\mathrm{NPP})+24.5\left[\mathrm{~g} \cdot \mathrm{C} / \mathrm{m}^{2} / \mathrm{yr}\right]$. This correlation does not conflict the result presented now, since it pointed out only a particular factor to spatial organization of the carbon cycle in biosphere.

\section{Discussion}

The problem of carbon dioxide accumulation in the atmosphere is directly related to the global carbon cycle functioning and the anthropogenic activity. Our studies allowed us to found the relationship between primary production and $\mathrm{CO}_{2}$ emission from soil that was important for understanding the current state of biosphere. Established as a result of a long-time process of forming structural and functional relations in biosphere, the equivalent relationship between NPP and SR may be viewed as an important criterion showing that the global 
system achieves a dynamic equilibrium (see Figure 2 and explanations in the text).

According to the current theory, the relationship between gross production and total respiration, $\mathrm{P} / \mathrm{R}$, approaches unity in the course of ecosystem development [22-24]. Hence, it is supposed that in mature communities the gross production is fully used for the energy exchange between components of the system and that the biomass buildup is actually equal to naught. It could be assumed that the present-day biosphere has already reached the state of dynamic equilibrium in its development. Nevertheless, it seems impossible to use the P/R ratio directly for the biosphere in general because of poor accuracy of estimates for total assimilation and respiration costs.

The man (or society) acts as a heterotrophic component in the global system (Figure 2). The nature of future relationship between the heterotrophic and autotrophic components, that is, between Man and Nature, will determine the fate of the earth population. That is why it is necessary to adopt a set of measures for preservation of the environment.

Thus, we currently have the only experimentally tested criterion of dynamic equilibrium in biosphere, NPP $\approx \mathrm{SR}$. At the present time, the impact of anthropogenic components on biosphere processes grows rather quickly. Assuming that the changed relationship between the autotrophic (nature) and the heterotrophic (society) components have no impact on the basic mechanism responsible for establishment of a dynamic equilibrium, it can be said that the new stable level should be determined by a relationship NPP $\approx \mathrm{SR}+\mathrm{E}_{\mathrm{h}}$. Here, $\mathrm{E}_{\mathrm{h}}$ is used to designate

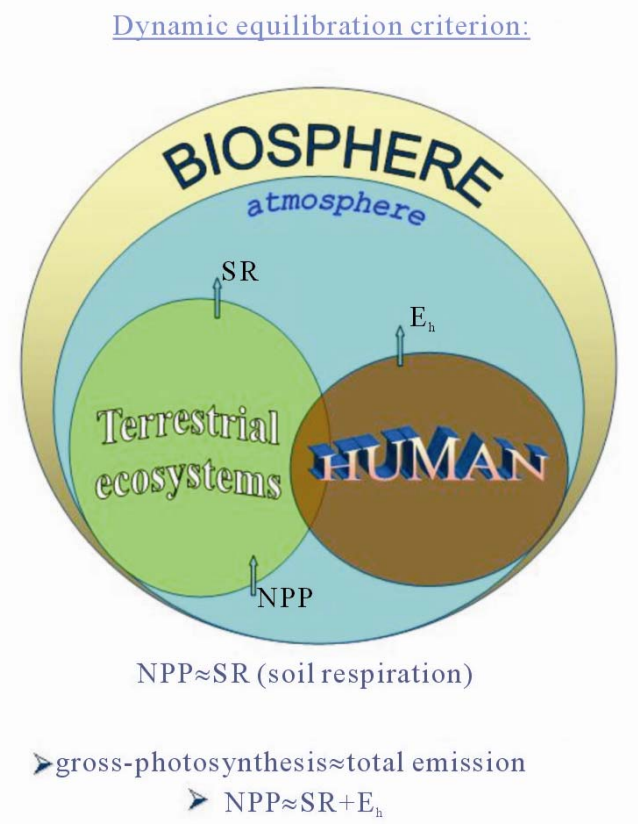

Figure 2. Dynamic equilibration criterion. the anthropogenic emission related to industrial production and activities of the man himself, whereas NPP and SR represent total values of net primary production and soil respiration, respectively, of natural, technogenic and agricultural ecosystems. If the nature of each component in this expression is taken into account, the dynamics of the global system could be forecasted with a higher degree of confidence.

Probably, existing picture about the main carbon sources and sinks without knowledge of mechanisms and factors, adjusting their relations in biosphere, is insufficient for explanation of the dynamic nature of the global phenomena [25]. For this score, NEP-concept of the carbon balancing [26] that postulate the sequestration or net ecosystem production (NEP) as NPP minus heterotrophic respiration $\mathrm{Rh}$ cannot be useful on global scale. An accounting of carbon flows differed from photosynthetic fixation and ecosystem respiration (net ecosystem carbon balance, NECB) [27], also leaves the researcher within the framework of existing paradigm of the carbon balancing. Received here results give us the strong footing to evolve the new global structure and functional organization model of carbon cycling in biosphere on the principal of self-regulation and self-organizing in consent with Lovelock's hypothesis of enormous planetary organism, adjusting environment for optimum development of the life [28].

\section{Conclusion}

The analysis described above allowed that an important relationship between the net primary production and the soil respiration of terrestrial ecosystems could be found. Being a one of fundamental nature, this relationship could be viewed as the basic criterion showing the establishment of a dynamic equilibrium in the biosphere. At the same time, this provides a reason for investigating biological carbon cycle processes on the global scale in more detail. The established regularity offers a new viewpoint from which the driving mechanism for tremendous masses of carbon on the earth can be studied.

\section{REFERENCES}

[1] J. T. Houghton, L. G. Meira Filho, B. A. Callander, N. Harris, A. Kattenberg and K. Maskell, "Climate Change 1995: The Science of Climate Change," Weather, Vol. 51, No. 11, 1996, p. 393. doi:10.1002/j.1477-8696.1996.tb06169.x

[2] M. Heimann and M. Reichstein, "Terrestrial Ecosystem Carbon Dynamics and Climate Feedbacks," Nature, Vol. 451, No. 7176, 2008, pp. 289-292. doi:10.1038/nature06591

[3] X. Xiao, J. M. Melillo, D. W. Kicklighter, A. D. McGuire, R. G. Prinn, C. Wang, P. H. Stone and A. Sokolov, "Transient Climate Change and Net Ecosystem Production of 
the Terrestrial Biosphere," Global Biogeochemical Cycles, Vol. 12, No. 2, 1998, pp. 345-360. doi:10.1029/98GB01035

[4] Y. P. Li and J. J. Ji, "Model Estimates of Global Carbon Flux between Vegetation and the Atmosphere," Advances in Atmospheric Sciences, Vol. 18, No. 5, 2001, pp. 807818.

[5] B. Wang, S. Yang and Y. Chen, "Effect of Climate Variables on the Modeling of Vegetation Net Primary Productivity in Karst Areas," Proceedings of 19th International Congress on Modeling and Simulation, Perth, 12-16 December 2011, pp. 2634-2640.

[6] J. M. O. Scurlock, W. Cramer, R. J. Olsson, W. J. Parton and S. D. Prince, "Terrestrial NPP: Towards a Consistent Data Set for Global Model Evaluation," Ecological Application, Vol. 9, No. 3, 1999, pp. 913-919. doi:10.1890/1051-0761(1999)009[0913:TNTACD]2.0.C $\mathrm{O} ; 2$

[7] G. L. Ajtay, P. Ketner and P. Duvigneaud, "Terrestrial Primary Production and Phytomass," In: B. Bolin, E. T. Degens, S. Kempe and P. Ketner, Eds., The Global Carbon Cycle, John Wiley \& Sons, Chichester, 1979, pp. 129-181.

[8] E. Box, "Geographical Dimensions of Terrestrial Net and Gross Primary Productivity," Radiation and Environmental Biophysics, Vol. 15, No. 4, 1978, pp. 305-322. doi:10.1007/BF01323458

[9] C. B. Field, M. J. Berenfeld, J. T. Randerson and P. Falkowski, "Primary Production of the Biosphere: Integrating Terrestrial and Oceanic Components," Science, Vol. 281, No. 5374, 1998, pp. 237-240. doi:10.1126/science.281.5374.237

[10] J. S. Olson, J. A. Watts and L. J. Allison, "Carbon in Live Vegetation of Major World Ecosystems," US Department of Energy, Carbon Dioxide Research Division, Washington, 1983.

[11] R. A. Houghton and G. M. Woodwell, "Global Climate Change," Scientific American, Vol. 260, No. 4, 1989, pp. 36-44. doi:10.1038/scientificamerican0489-36

[12] J. W. Raich and W. H. Schlesinger, "The Global Carbon Dioxide Flux in Soil Respiration and Its Relation to Vegetation and Climate," Tellus B, Vol. 44, No. 2, 1992, pp. 81-99. doi:10.1034/j.1600-0889.1992.t01-1-00001.x

[13] L. E. Rodin and N. I. Bazilevich, "Production and Mineral Cycling in Terrestrial Vegetation," Oliver and Boyd, Edinburg, 1967.

[14] W. H. Schlesinger, "Carbon Balance in Terrestrial Detritus," Annual Review of Ecology and Systematics, Vol. 8, No. 1, 1977, pp. 51-81. doi:10.1146/annurev.es.08.110177.000411

[15] E. Matthews, "Global Vegetation and Land Use," Journal of Climate and Applied Meteorology, Vol. 22, No. 3, 1983, pp. 474-487. doi:10.1175/1520-0450(1983)022<0474:GVALUN>2.0. $\underline{\mathrm{CO} ; 2}$
[16] V. V. Dobrovolski, "Fundamentals of Biogeochemistry," High School, Moscow, 1998.

[17] H. F. H. Lieth and R. H. Whitteker, "Primary Productivity of the Biosphere," Springer-Verlag, Berlin, 1975. doi:10.1007/978-3-642-80913-2

[18] J. W. Raich and C. S. Potter, "Global Patterns of Carbon Dioxide Emissions from Soils," Global Biogeochemical Cycles, Vol. 9, No. 1, 1995, pp. 23-36. doi:10.1029/94GB02723

[19] J. W. Raich, C. S. Potter and D. Bhagawati, "Interannual Variability in Global Soil Respiration, 1980-1994," Global Change Biology, Vol. 8, No. 8, 2002, pp. 800-812. doi:10.1046/j.1365-2486.2002.00511.x

[20] N. I. Bazilevich and A. A. Titlyanova, "Biotic Turnover on Five Continents: Element Exchange Processes in Terrestrial Natural Ecosystems," Publishing House SB RAS, Novosibirsk, 2008.

[21] A. V. Naumov, "Soil Respiration: Constituents, Ecological Functions, Geographic Patterns," Publishing House SB RAS, Novosibirsk, 2009.

[22] H. T. Odum, "Primary Production in Flowing Waters," Limnology and Oceanography, Vol. 1, No. 2, 1956, pp. 102-117. doi:10.4319/1o.1956.1.2.0102

[23] E. P. Odum, "Fundamentals of Ecology," 3rd Edition, W.B. Saunders Company, Philadelphia-London-Toronto, 1971.

[24] W. Larcher, "Ökologie der Pflanzen,” 2. Auflage, Verlag, Eugen Ulmer, Stuttgart, 1976.

[25] R. A. Houghton, "Balancing the Global Carbon Budget," Annual Review of Earth and Planetary Sciences, Vol. 35, No. 1, 2007, pp. 313-347. doi:10.1146/annurev.earth.35.031306.140057

[26] G. M. Woodwell and R. H. Whitteker, "Primary Production in Terrestrial Communities," Integrative and Comparative Biology, Vol. 8, No. 1, 1968, pp. 19-30. doi:10.1093/icb/8.1.19

[27] F. S. Chapin III, G. M. Woodwell, J. T. Randerson, E. B. Rastetter, G. M. Lovett, D. D. Baldocchi, D. A. Clark, M. E. Harmon, D. S. Schimel, R. Valentini, C. Wirth, J. D. Aber, J. J. Cole, M. L. Goulden, J. W. Harden, M. Heimann, R. W. Howarth, P. A. Matson, A. D. McGuire, J. M. Melillo, H. A. Mooney, J. C. Neff, R. A. Houghton, M. L. Pace, M. G. Ryan, S. W. Running, O. E. Sala, W. H. Schlesinger and E.-D. Schulze, "Reconciling CarbonCycle Concepts, Terminology, and Methods," Ecosystems, Vol. 9, No. 7, 2006, pp. 1041-1050. doi:10.1007/s10021-005-0105-7

[28] J. E. Lovelock, "Geophysiology: A New Look at Earth Science," Bulletin of the American Meteorological Society, Vol. 67, No. 4, 1986, pp. 392-397. 